\title{
HMOX1 as a marker of iron excess-induced adipose tissue dysfunction, affecting glucose uptake and respiratory capacity in human adipocytes
}

\author{
José María Moreno-Navarrete ${ }^{1,2}$ - Francisco Ortega ${ }^{1,2}$ - Amaia Rodríguez ${ }^{2,3}$. \\ Jèssica Latorre $^{1,2}$ - Sara Becerril ${ }^{2,3}$ - Mònica Sabater-Masdeu ${ }^{1,2}$ - Wifredo Ricart ${ }^{1,2,4}$. \\ Gema Frühbeck $^{2,3}$ • José Manuel Fernández-Real ${ }^{1,2,4}$
}

Received: 26 October 2016 / Accepted: 1 February 2017 / Published online: 27 February 2017

(C) Springer-Verlag Berlin Heidelberg 2017

\begin{abstract}
Aims/hypothesis Iron excess in adipose tissue is known to promote adipose tissue dysfunction. Here, we aimed to investigate the possible role of haem oxygenase 1 (HMOX1) in iron excess-induced adipose tissue dysfunction.

Methods Cross-sectionally, HMOX1 gene expression in subcutaneous and visceral adipose tissue was analysed in two independent cohorts ( $n=234$ and 40$)$ in relation to obesity. We also evaluated the impact of weight loss $(n=21)$, weight gain (in rats, $n=20$ ) on $H M O X 1 \mathrm{mRNA}$; $H O X 1 \mathrm{mRNA}$ levels during human adipocyte differentiation; the effects of inflammation and iron on adipocyte HMOX1; and the effects of HMOX1-induced activity on adipocyte mitochondrial respiratory function, glucose uptake and adipogenesis.
\end{abstract}

José María Moreno-Navarrete and José Manuel Fernández-Real contributed equally to this study.

Electronic supplementary material The online version of this article (doi:10.1007/s00125-017-4228-0) contains peer-reviewed but unedited supplementary material, which is available to authorised users.

José María Moreno-Navarrete jmoreno@idibgi.org

$\triangle$ José Manuel Fernández-Real jmfreal@idibgi.org

1 Department of Diabetes, Endocrinology and Nutrition, Institut d'Investigació Biomèdica de Girona (IdIBGi), Hospital of Girona 'Dr Josep Trueta', Carretera de França s/n, 17007 Girona, Spain

2 Centro de Investigación Biomédica en Red de Fisiopatología de la Obesidad y Nutrición (CIBEROBN), Instituto de Salud Carlos III (ISCIII), Spain,

http://www.ciberobn.es

3 Metabolic Research Laboratory, Clínica Universidad de Navarra, Pamplona 31008, Spain

4 Department of Medicine, Universitat de Girona, Girona 17007, Spain
Results Adipose tissue $H M O X 1$ was increased in obese participants $(p=0.01)$ and positively associated with obesityrelated metabolic disturbances, and markers of iron accumulation, inflammation and oxidative stress $(p<0.01)$. HMOX1 was negatively correlated with mRNAs related to mitochondrial biogenesis, the insulin signalling pathway and adipogenesis $(p<0.01)$. These associations were replicated in an independent cohort. Bariatric surgery-induced weight loss led to reduced $H M O X 1(0.024 \pm 0.010$ vs $0.010 \pm 0.004 \mathrm{RU}$, $p<0.0001$ ), whereas in rats, high-fat diet-induced weight gain resulted in increased Hmoxl mRNA levels $(0.22 \pm 0.15$ vs $0.54 \pm 0.22 \mathrm{RU}, p=0.005)$. These changes were in parallel with changes in BMI and adipose tissue markers of iron excess, adipogenesis and inflammation. In human adipocytes, iron excess and inflammation led to increased HMOX1 mRNA levels. HMOX1 induction (by haem arginate [hemin] administration), resulted in a significant reduction of mitochondrial respiratory capacity (including basal respiration and spare respiratory capacity), glucose uptake and adipogenesis in parallel with increased expression of inflammatoryand iron excess-related genes.

Conclusions/interpretation HMOX1 is an important marker of iron excess-induced adipose tissue dysfunction and metabolic disturbances in human obesity.

Keywords Adipogenesis - Adipose tissue $\cdot$ HMOX1 - Iron · Obesity
Abbreviations
DFO Deferoxamine
eWAT Epididymal white adipose tissue
HFD High-fat diet
HMOX1 Haem oxygenase 1 


$\begin{array}{ll}\text { MCM } & \text { Macrophage-conditioned medium } \\ \text { ROS } & \text { Reactive oxygen species } \\ \text { SAT } & \text { Subcutaneous adipose tissue } \\ \text { SVF } & \text { Stromal vascular fraction } \\ \text { VAT } & \text { Visceral adipose tissue }\end{array}$

\section{Introduction}

Adipose tissue dysfunction is a hallmark of obesity-associated metabolic disturbances. It is characterised by a significant reduction in its capacity to store excess fuel $[1,2]$ and to generate new adipocytes (adipogenesis) [3, 4] in parallel with increased levels of inflammatory markers, as a consequence of macrophage infiltration [5] and adipocyte inflammation [6].

Recent studies demonstrated that iron excess in adipose tissue promotes adipose tissue dysfunction, leading to decreased adipogenesis and enhanced adipocyte inflammation and adipose tissue macrophage M1 polarisation [7-12]. Intracellular mediators of iron homeostasis contribute to changes in adipose tissue physiology and adipogenesis, including SLC40A1 or ferroportin [9], transferrin [11], cytosolic aconitase [13] and mitoNEET [14, 15], but less is known about the source of iron excess.

Haem oxygenase 1 (HMOX1, also known as HO-1) is an inducible enzyme required for haem degradation. Since haem degradation leads to the production of biliverdin, ferrous iron and carbon monoxide, haem oxygenase activity is an important source of intracellular iron. Taking into account that high dietary intake of haem iron, which is more easily absorbed than non-haem iron [16], is considered a risk factor in the progression of type 2 diabetes and obesity-associated metabolic disturbances [16-19], and the importance of intracellular haem levels in adipogenesis [20], we hypothesised that increased adipose tissue HMOX1 activity (an extra source of iron) might contribute to obesity-associated adipose tissue iron excess and, in consequence, promote adipose tissue dysfunction. In line with this hypothesis, a recent study demonstrated that macrophage HMOX1 is required to promote adipose tissue inflammation in mice [21]. Specifically, macrophage HMOX1 deletion improved adipose tissue dysfunction, inhibiting the development of crown-like structures and macrophage infiltration, reducing adipocyte hypertrophy and increasing the expression of adipogenic genes and the number of protective M2 macrophages. Furthermore, this study also showed that the inhibition of HMOX1 activity in liver and in macrophages improved glucose clearance and insulin sensitivity, and decreased high-fat diet (HFD)-induced inflammation [21]. In contrast to this study, two previous studies in murine models demonstrated that systemic induction of HMOX1 activity by intraperitoneal cobalt protoporphyrin administration resulted in reduced adiposity, increased circulating adiponectin and improved insulin sensitivity and glucose tolerance $[22,23]$.
In humans, a few studies have examined $H M O X 1$ gene expression in adipose tissue. Specifically, Shakeri-Manesch et al reported the first study showing increased subcutaneous (SAT) and visceral (VAT) adipose tissue HMOX1 mRNA and protein levels in obese participants (morbidly obese $[n=20] \mathrm{vs}$ non-obese $[n=20]$ ) [24]. VAT HMOX1 expression was negatively correlated with HOMA-IR [24]. Two additional studies confirmed increased SAT $(n=42$ [25]) and VAT $(n=50$ [21]) $H M O X 1$ gene expression in obese participants, but in positive association with insulin resistance. In one of these studies the significance of the correlation between SAT HMOXI mRNA and insulin resistance was lost after controlling for BMI [25]. The studies indicate a clear association between adipose tissue HMOXI expression and adiposity. However, the association with insulin resistance remains controversial.

To the best of our knowledge the possible role of HMOX1 in the relationship between iron metabolism and adipogenesis in human adipose tissue and adipocytes has not been explored. In the current study, we aimed to investigate the possible role of HMOX1 in human adipose tissue, adipogenesis and iron metabolism. To this end, we evaluated (1) SAT and VAT $H M O X 1$ gene expression in two independent cohorts in relation with obesity; (2) the impact of weight loss and weight gain (in rats) on adipose tissue HMOX1; (3) HMOX1 mRNA levels during human adipocyte differentiation; (4) the effects of inflammation, iron and haem arginate (hemin) on adipocyte HMOX1; and (5) the effects of induction of HMOX1 activity on adipocyte mitochondrial respiratory function, glucose uptake and adipogenesis.

\section{Methods}

Patient recruitment Adipose tissue samples were obtained from three independent cohorts. In cohort 1, a group of 234 adipose tissue samples (120 VAT and 114 SAT) from participants with normal body weight and different degrees of obesity (BMI ranging from 20 to $68 \mathrm{~kg} / \mathrm{m}^{2}$ ) were analysed. In cohort 2, which comprised morbidly obese (BMI $>35 \mathrm{~kg} / \mathrm{m}^{2}$ ) participants with different degrees of insulin action (measured using hyperinsulinaemic-euglycaemic clamp [9] as detailed in the electronic supplementary material [ESM] Methods), 40 paired SAT and VAT samples were studied. All these participants were recruited at the Endocrinology Service of the Hospital of Girona 'Dr Josep Trueta'. All participants gave written informed consent, validated and approved by the Ethics Committee of the Hospital of Girona 'Dr Josep Trueta', after the purpose of the study was explained to them.

In cohort 3, 21 obese $(47 \pm 9$ years [mean $\pm \mathrm{SD}])$ participants of European descent, who underwent bariatric surgery via Roux-en-Y gastric bypass (RYGB) at the Hospital of Girona 'Dr Josep Trueta' were part of an ongoing study $[9,14]$. Adipose tissue samples from the SAT depot were 
obtained during bariatric surgery. Postoperative samples of SAT were obtained by subcutaneous biopsy at the mesogastric level 2 years after surgery. All participants gave written informed consent, validated and approved by the Ethics Committee of the Hospital of Girona 'Dr Josep Trueta', after the purpose of the study was explained to them.

Additional information is detailed in ESM Methods.

Adipose tissue handling Adipose tissue samples were obtained from SAT and VAT (omentum) depots during elective surgical procedures (cholecystectomy, abdominal hernia surgery and gastric bypass surgery). Samples of adipose tissue were immediately transported to the laboratory (5-10 $\mathrm{min})$. The handling of tissue was carried out under strictly aseptic conditions. Adipose tissue samples were washed in PBS, cut with forceps and scalpel into small pieces $(100 \mathrm{mg})$ and immediately flash-frozen in liquid nitrogen before being stored at $-80^{\circ} \mathrm{C}$. The isolation of adipocyte and stromal vascular fraction (SVF) cells was performed from nine non-frozen SAT samples as described in the ESM Methods.

Effects of weight gain in rats Four-week-old male Wistar rats $(n=20)$ were randomised into two groups fed ad libitum during an average of 6 months either a normal chow diet $(n=10)$ for comparative purposes or an HFD $(n=10)$ to induce obesity. These experiments are detailed in the ESM Methods. All experimental procedures conformed to the European Guidelines for the Care and Use of Laboratory Animals (directive 2010/63/EU) and were approved by the Ethics Committee for Animal Experimentation of the University of Navarra (049/10). No data from these experiments has been excluded.

Differentiation of human pre-adipocytes Differentiation of human pre-adipocytes is described in the ESM Methods. For the time course experiment, cells were harvested and stored at $-80^{\circ} \mathrm{C}$ for RNA extraction at day $0,2,5,7,9,12$ and 14 . The effect of administration of (1) macrophage-conditioned medium (MCM, 2.5\%) from THP-1 cells previously treated with lipopolysaccharide (10 $\mathrm{ng} / \mathrm{ml}$ for $24 \mathrm{~h})$, (2) hemin $(60 \mu \mathrm{mol} / \mathrm{l})$, (3) $\mathrm{FeSO}_{4}(3$ and $30 \mu \mathrm{g} / \mathrm{ml}$ ) or (4) deferoxamine (DFO, $20 \mu \mathrm{mol} / \mathrm{l})$ during subcutaneous adipocyte differentiation was studied. Otherwise, before and after adipocyte differentiation (at day 0 and day 14), subcutaneous pre-adipocytes and fully differentiated adipocytes were incubated with fresh medium (control) or fresh medium containing several treatments. These treatments included hemin $(60 \mu \mathrm{mol} / \mathrm{l}), \mathrm{FeSO}_{4}(3$ and $30 \mu \mathrm{g} / \mathrm{ml})$ and DFO $(20 \mu \mathrm{mol} / \mathrm{l})$. After 48 and $72 \mathrm{~h}$, cells were harvested, and pellets and supernatants were stored at $-80^{\circ} \mathrm{C}$. The concentrations of these treatments were selected and optimised according to previous reports $[10,20]$. All in vitro experiments were randomised and performed in triplicate. Experimenters were blind to group assignment and outcome assessment. No data from these experiments has been excluded.
Glucose uptake Adipocyte glucose uptake was measured using the Glucose Uptake Assay Kit (ab136955, Abcam, Cambridge, UK) as described in the ESM Methods.

Mitochondrial respiratory function Mitochondrial respiratory function was assessed using the Seahorse XFp Extracellular Flux Analyzer (Seahorse Bioscience, Agilent Technologies, Santa Clara, CA, USA) using the Seahorse XFp Cell Mito Stress Test Kit according to the manufacturer's instructions.

RNA expression RNA purification, gene expression procedures and analyses were carried out as previously described [9, 14]. Briefly, RNA purification was performed using an RNeasy Lipid Tissue Mini Kit (QIAgen, Izasa, Barcelona, Spain) and the integrity was checked using an Agilent Bioanalyzer (Agilent Technologies, Palo Alto, CA, USA). Gene expression was assessed by real-time PCR using a LightCycler 480 Real-Time PCR System (Roche Diagnostics, Barcelona, Spain), using TaqMan and SYBR green technology suitable for relative genetic expression quantification. The commercially available and pre-validated TaqMan primer/ probe sets used are detailed in the ESM Methods.

Adipose tissue protein extraction VAT $(n=40)$ and SAT $(n=26)$ protein were extracted as described in the ESM Methods. HMOX1 protein levels were measured using Human HO 1 ELISA kit (ab133064, Abcam) in adipose tissue extracts following manufacturer's instructions. Total iron was measured using the Iron-FerroZine colorimetric method following the manufacturer's protocol (11509, Biosystems, Barcelona, Spain). The same amount of total protein $(100 \mu \mathrm{g})$ was used to perform these measurements.

Analytical methods Serum glucose, insulin, homeostasis model assessment of insulin resistance (HOMA-IR), HDL-cholesterol, fasting triacylglycerols and $\mathrm{C}$-reactive protein concentration were measured as previously described $[9,14]$.

Statistical analyses Statistical analyses were performed using SPSS 12.0 software. Unless otherwise stated, descriptive results of continuous variables are expressed as mean and SD for Gaussian variables or median and interquartile range. Variables that did not fulfill normal distribution criteria were $\log _{10}$ transformed to improve symmetry for subsequent analyses. The relation between variables was analysed by simple correlation (Pearson's test and Spearman's test) and multiple regression analyses in a stepwise manner. One-factor ANOVA with post hoc Bonferroni test, paired $t$ test and unpaired Student's $t$ test were used to compare $H M O X 1$ gene expression according to obesity and type 2 diabetes. A nonparametric test (MannWhitney $U$ test) was used to analyse in vitro experiments. Levels of statistical significance were set at $p<0.05$. 


\section{Results}

HMOX1 mRNA in human adipose tissue Anthropometric and clinical variables of participants in cohort 1 are shown in Table 1. No significant differences in SAT and VAT $H M O X 1$ expression were found in non-obese $(0.019 \pm 0.01$ vs $0.020 \pm 0.02, p=0.7)$ and obese participants $(0.030 \pm 0.01$ vs $0.031 \pm 0.01, p=0.6)$. In both SAT and VAT, HMOXI gene expression was significantly increased in obese participants (Table 1). Both SAT and VAT HMOX1 gene expression was associated with BMI, but not with fasting glucose (Table 2). In this cohort, the increased SD of fasting glucose in obese compared with non-obese participants $(6.2 \pm 2.5 \mathrm{vs}$ $5.0 \pm 0.5 \mathrm{mmol} / 1[\mathrm{mean} \pm \mathrm{SD}])$ might explain the lack of association between adipose tissue $H M O X 1$ and fasting glucose in these participants. In obese participants, both SAT and VAT $H M O X 1$ gene expression values above the first quartile were significantly associated with increased fasting glucose (ESM Table 1, Fig. 1). VAT HMOXI gene expression was also positively correlated with fasting triacylglycerols (Table 2). However, this correlation was lost $(r=0.06, p=0.5)$ after controlling for BMI.

$H M O X 1$ gene expression was negatively correlated with adipogenic (PPARG, FASN, ACACA, SLC2A4), insulin pathway-related (IRS1) and mitochondrial biogenesis-related (PPARGC1A [only in SAT], MTCO3) genes, and positively correlated with markers of inflammation (TNF, IL10, IL6, $I L 8)$, iron accumulation (FTL, SLC40A1) and oxidative stress (CYBA, NFE2L2) in both SAT and VAT (Table 2). HMOX1 gene expression was negatively correlated with $C D 206$ (also known as $M R C 1) / C D 68$ ratio (a specific marker of $\mathrm{M} 2$ macrophages) in VAT, but not with expression of the non-specific classical macrophage marker, $C D 68$ (Table 2). In multivariate
Table 2 Bivariate correlation among clinical variables, expression of $H M O X 1$ gene and expression of adipose tissue-related genes in VAT and SAT from cohort 1

\begin{tabular}{|c|c|c|c|c|}
\hline \multirow[t]{2}{*}{ Variable } & \multicolumn{2}{|l|}{ VAT } & \multicolumn{2}{|l|}{ SAT } \\
\hline & $r$ & $p$ value & $r$ & $p$ value \\
\hline Age (years) & -0.09 & 0.3 & -0.15 & 0.1 \\
\hline BMI $\left(\mathrm{kg} / \mathrm{m}^{2}\right)$ & 0.32 & 0.002 & 0.27 & 0.01 \\
\hline Fasting glucose $(\mathrm{mmol} / \mathrm{l})$ & 0.12 & 0.2 & 0.12 & 0.2 \\
\hline Fasting triacylglycerol $(\mathrm{mmol} / \mathrm{l})$ & 0.22 & 0.04 & 0.18 & 0.08 \\
\hline HDL-cholesterol (mmol/l) & -0.09 & 0.3 & -0.015 & 0.8 \\
\hline$P P A R G(\mathrm{RU})$ & -0.31 & 0.003 & -0.51 & $<0.000$ \\
\hline$S L C 2 A 4$ (RU) & -0.42 & $<0.0001$ & -0.55 & $<0.000$ \\
\hline IRSI (RU) & -0.44 & $<0.0001$ & -0.31 & 0.003 \\
\hline FASN (RU) & -0.27 & 0.005 & -0.36 & $<0.000$ \\
\hline$A C A C A(\mathrm{RU})$ & -0.43 & $<0.0001$ & -0.29 & 0.003 \\
\hline PPARGCIA (RU) & 0.04 & 0.6 & -0.33 & 0.002 \\
\hline MTCO3 (RU) & -0.29 & 0.003 & -0.39 & $<0.000$ \\
\hline$T N F(\mathrm{RU})$ & 0.25 & 0.02 & 0.24 & 0.03 \\
\hline IL10 (RU) & 0.51 & $<0.0001$ & 0.43 & $<0.000$ \\
\hline IL6 (RU) & 0.37 & 0.001 & 0.31 & 0.003 \\
\hline IL8 (RU) & 0.42 & $<0.0001$ & 0.38 & $<0.000$ \\
\hline FTL (RU) & 0.49 & $<0.0001$ & 0.26 & 0.02 \\
\hline$C Y B A(\mathrm{RU})$ & 0.38 & 0.001 & 0.23 & 0.04 \\
\hline SLC40A1 (RU) & 0.33 & 0.003 & 0.39 & $<0.000$ \\
\hline$N F E 2 L 2(\mathrm{RU})$ & 0.48 & $<0.0001$ & 0.34 & 0.002 \\
\hline CD68 (RU) & 0.09 & 0.4 & 0.17 & 0.1 \\
\hline$C D 206 / C D 68$ & -0.26 & 0.01 & -0.21 & 0.06 \\
\hline
\end{tabular}

The data are expressed as mean $\pm \mathrm{SD}$ or median (interquartile range) $\mathrm{RU}$, relative units of gene expression relative to PPIA as endogenous control
Table 1 Anthropometric and clinical variables of study participants from cohort 1 and cohort 2

\begin{tabular}{|c|c|c|c|c|}
\hline \multirow[b]{2}{*}{ Variable } & \multicolumn{3}{|l|}{ Cohort 1} & \multirow{2}{*}{$\begin{array}{l}\text { Cohort } 2 \\
\text { Morbidly obese } \\
\left(\mathrm{BMI}>35 \mathrm{~kg} / \mathrm{m}^{2}\right)\end{array}$} \\
\hline & Non-obese & Obese & $p$ value & \\
\hline$N$ & 22 & 98 & & 40 \\
\hline Sex (men/women) & $10 / 12$ & $21 / 77$ & & $9 / 31$ \\
\hline Age (years) & $51.3 \pm 14.3$ & $45.6 \pm 11.2$ & 0.1 & $47.6 \pm 7.9$ \\
\hline BMI $\left(\mathrm{kg} / \mathrm{m}^{2}\right)$ & $26.6 \pm 2.7$ & $44.7 \pm 6.1$ & $<0.0001$ & $45.8 \pm 6.7$ \\
\hline Fasting glucose $(\mathrm{mmol} / \mathrm{l})$ & $4.9(4.4,5.5)$ & $5.4(4.9,6.4)$ & 0.03 & $5.4(4.9,5.9)$ \\
\hline HOMA-IR & - & - & - & $3.91(2.31,5.84)$ \\
\hline$M$ value $\left(\mu \mathrm{mol} \mathrm{kg}{ }^{-1} \min ^{-1}\right)$ & - & - & - & $14.9(10.1,24.1)$ \\
\hline Fasting triacylglycerol $(\mathrm{mmol} / \mathrm{l})$ & $1.11(0.79,1.77)$ & $1.15(0.90,1.64)$ & 0.7 & $1.3(0.96,1.69)$ \\
\hline HDL-cholesterol (mmol/l) & $1.52(1.20,1.92)$ & $1.35(1.13,1.63)$ & 0.6 & $1.12(1.03,1.28)$ \\
\hline VAT $H M O X 1$ mRNA (RU) & $0.020 \pm 0.017$ & $0.031 \pm 0.015$ & 0.01 & $0.032 \pm 0.018$ \\
\hline SAT $H M O X 1$ mRNA (RU) & $0.019 \pm 0.012$ & $0.030 \pm 0.013$ & 0.001 & $0.041 \pm 0.019$ \\
\hline
\end{tabular}

The data are expressed as mean $\pm \mathrm{SD}$ or median (interquartile range)

$\mathrm{RU}$, relative units of gene expression relative to PPIA as endogenous control 
Fig. 1 (a, b) Fasting glucose according to VAT (a) and SAT (b) $H M O X 1$ gene expression first quartile in cohort 1. (c, d) Fasting glucose according to VAT (c) and SAT (d) $H M O X 1$ gene expression first quartile in cohort $2 . * p<0.05$ compared with $H M O X 1$ mRNA $(\mathrm{RU})<1$ st quartile. Error bars show $95 \%$ CI. In cohort 1 , $H M O X 1$ gene expression values were $0.028(0.021-0.038) \mathrm{RU}$ in SAT and $0.027(0.019-0.036)$ RU in VAT (median and interquartile range) and the first quartiles were $0.021 \mathrm{RU}$ in SAT and 0.019 RU in VAT. In cohort 2, HMOXI gene expression values were 0.033 $(0.027-0.048) \mathrm{RU}$ in SAT and $0.031(0.020-0.042) \mathrm{RU}$ in VAT (median and interquartile range) and the first quartiles were 0.027 RU in SAT and 0.020 RU in VAT a

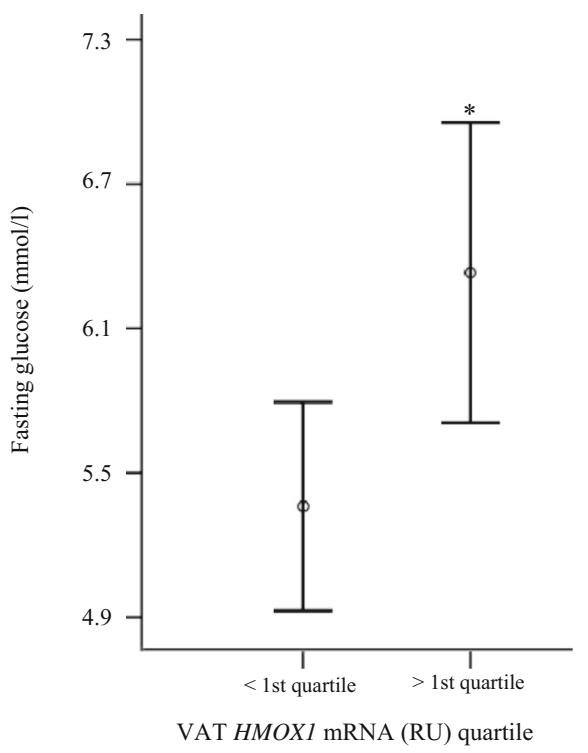

C

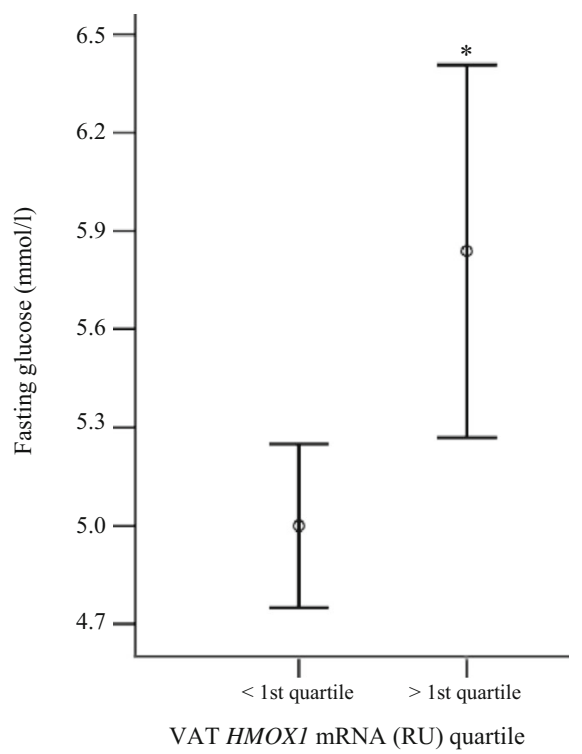

b

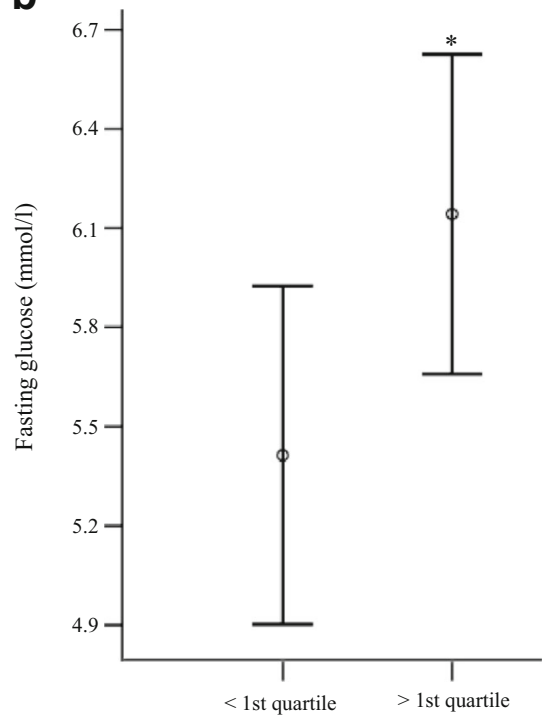

SAT HMOX1 mRNA (RU) quartile

d

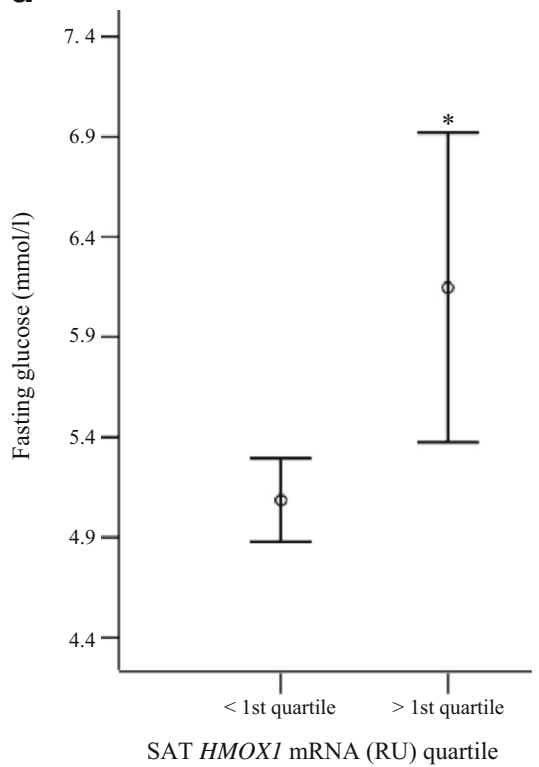

regression analysis, all these gene expression associations (except IRS1 in SAT and CD206/CD68 in VAT) remained significant after controlling for age and BMI in both VAT (ESM Table 2) and SAT (ESM Table 3).

In a subgroup of participants, HMOX1 protein and total iron levels were measured. Significant associations among HMOX1 mRNA, HMOX1 protein and total iron levels in both VAT (Fig. 2a-c) and SAT (Fig. 2d-f) were found. HMOX1 mRNA, HMOX1 protein and total iron levels were increased in those participants with BMI over $35 \mathrm{~kg} / \mathrm{m}^{2}$ (ESM Fig. 1).

A second independent cohort (cohort 2) composed of morbidly obese patients confirmed the association between $H M O X 1$ gene expression and markers of intracellular iron excess (SLC40A1 [ $r=0.41, p=0.03]$, FTL $[r=0.46, p=0.005]$ and $C Y B A[r=0.61, p<0.0001])$ and inflammation (TNF $[r=0.58, p<0.0001], \operatorname{LBP}[r=0.53, p=0.001])$. The association between both SAT and VAT HMOXI gene expression values above the first quartile and fasting glucose were also replicated in cohort 2 (ESM Table 1, Fig. 1). SAT HMOXI gene expression values above the first quartile were also associated with HOMA-IR (ESM Table 1). In this cohort, HMOXI gene expression was non-significantly increased in SAT vs $\operatorname{VAT}(0.041 \pm 0.019$ vs $0.032 \pm 0.018 p=0.06)$.

Effects of bariatric surgery-induced weight loss In cohort 3, bariatric surgery-induced weight loss resulted in decreased SAT HMOX1 mRNA levels (Table 3). The per cent change in $H M O X 1 \mathrm{mRNA}$ levels was positively correlated with the 
Fig. 2 Bivariate correlations among $H M O X 1$ gene expression, HMOX1 protein and total iron levels in VAT $(\mathbf{a}-\mathbf{c})$ and SAT $(\mathbf{d}-$ f). $\log$ indicates $\log _{10}$ transformation a
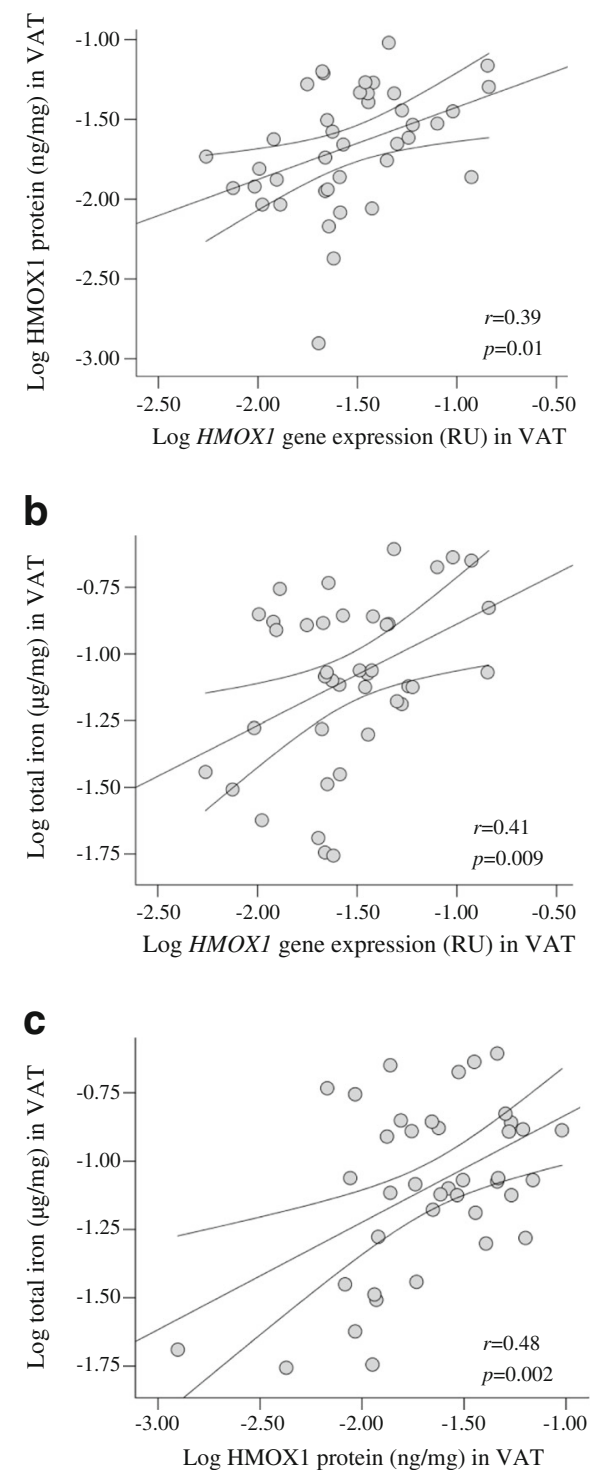

d

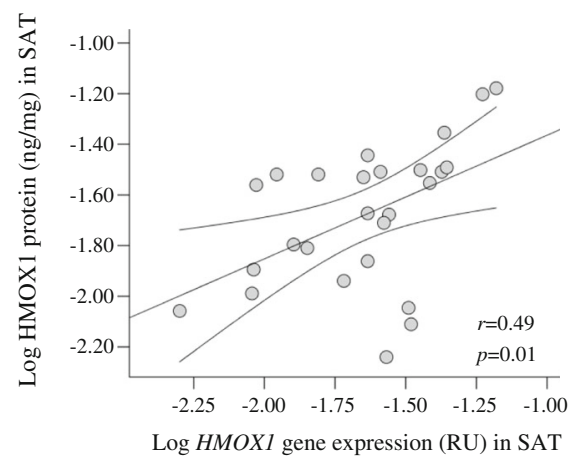

e

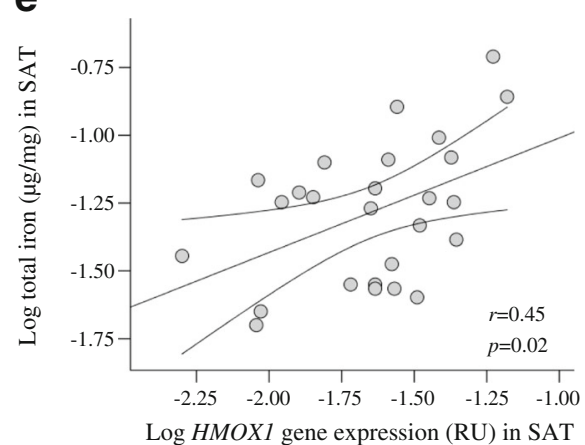

f

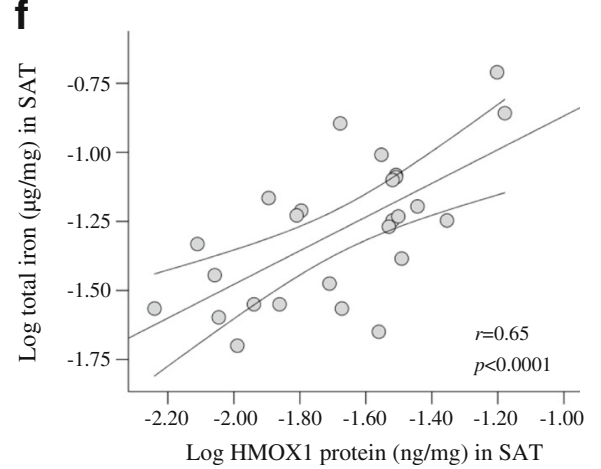

per cent change in weight $(r=0.51, p=0.01)$, BMI $(r=0.60$, $p=0.004)$ and fat mass $(r=0.66, p=0.001)$, but not with the per cent change in fasting glucose, HDL-cholesterol, fasting triacylglycerols, C-reactive protein or insulin sensitivity (estimated using $M$ value) (Table 3). In addition, the per cent change in HMOX1 mRNA levels was negatively correlated with the per cent change in adipogenic (ADIPOQ, SLC2A4) gene expression and positively correlated with the per cent change in intracellular iron excess-related (SLC4OA1, FTL) gene expression (Table 3). No correlation was found between the per cent change in $H M O X 1$ and inflammatory-related (TNF, IL6, IL8, CD14) gene expression (Table 3).

Effects of HFD-induced weight gain in rats HFD-induced weight gain resulted in increased Hmoxl mRNA levels in epididymal white adipose tissue (eWAT), positively correlated with weight, eWAT weight, HOMA-IR, circulating leptin and eWAT Il6, and negatively correlated with Adipoq mRNA levels (Fig. 3a-i).

HMOX1 in human adipogenesis $H M O X 1$ mRNA levels progressively decreased during differentiation of human adipocytes (Fig. 4a). The analysis of adipose tissue subfractions showed that HMOX1 mRNA levels were significantly reduced in adipocytes compared with SVF cells (including $\mathrm{CD}^{+} 4^{+}$and $\mathrm{CD} 14^{-}$cells) (Fig. 4b), with the highest expression being shown in $\mathrm{CD} 14^{+}$cells (enriched with adipose tissue macrophages) (Fig. 4b). Inflammatory conditions (MCM, 2.5\%; Fig. 4c) and iron (Fig. 4d) administration during adipocyte differentiation induced $H M O X 1$ mRNA levels. Iron administration in pre-adipocytes (Fig. 4e) and fully differentiated adipocytes (Fig. 4f) also resulted in increased HMOXI 
Table 3 Effects of bariatric-surgery-induced weight loss on $H M O X 1$ gene expression, anthropometric and clinical variables and other gene expression in SAT in cohort 3

\begin{tabular}{llllll}
\hline & Pre-surgery $(n=21)$ & Post-surgery $(n=21)$ & $p$ value & $r^{\mathrm{a}}$ & $p$ value \\
\hline Weight $(\mathrm{kg})$ & $116.6 \pm 17.7$ & $78.9 \pm 17.9$ & $<0.0001$ & 0.51 & 0.01 \\
BMI $\left(\mathrm{kg} / \mathrm{m}^{2}\right)$ & $43.5 \pm 5.1$ & $29.6 \pm 5.6$ & $<0.0001$ & 0.60 & 0.004 \\
Fat mass $(\%)$ & $56.8 \pm 7.6$ & $40.8 \pm 7.4$ & $<0.0001$ & 0.66 & 0.001 \\
Fasting glucose $(\mathrm{mmol} / \mathrm{l})$ & $5.3 \pm 0.7$ & $4.9 \pm 0.7$ & 0.03 & 0.25 & 0.3 \\
M value $\left(\mu \mathrm{mol} \mathrm{kg} \mathrm{min}^{-1}\right)$ & $21.9 \pm 12.8$ & $30.5 \pm 14.9$ & 0.02 & 0.27 & 0.3 \\
HDL-cholesterol $(\mathrm{mmol} / \mathrm{l})$ & $1.45 \pm 0.35$ & $1.89 \pm 0.58$ & 0.001 & -0.10 & 0.6 \\
Triacylglycerol $(\mathrm{mmol} / \mathrm{l})$ & $1.14(0.73,1.67)$ & $0.80(0.64,1.03)$ & 0.005 & 0.04 & 0.8 \\
C-reactive protein $(\mathrm{nmol} / 1)$ & $42.8(28.6,104.7)$ & $4.7(2.8,9.5)$ & 0.003 & 0.31 & 0.2 \\
ADIPOQ (RU) & $2.92 \pm 1.3$ & $4.17 \pm 1.9$ & 0.02 & -0.45 & 0.04 \\
SLC2A4 (RU) & $0.035 \pm 0.02$ & $0.093 \pm 0.05$ & $<0.0001$ & -0.54 & 0.01 \\
FTL (RU) & $17.1 \pm 6.6$ & $10.5 \pm 7.8$ & 0.005 & 0.49 & 0.03 \\
SLC40A1 (RU) & $0.17 \pm 0.10$ & $0.10 \pm 0.036$ & 0.008 & 0.59 & 0.009 \\
TNF (RU) & $0.0028 \pm 0.0019$ & $0.00078 \pm 0.0003$ & $<0.0001$ & -0.36 & 0.1 \\
IL6 (RU) & $0.0013 \pm 0.0009$ & $0.0005 \pm 0.0003$ & 0.003 & -0.39 & 0.07 \\
IL8 (RU) & $0.018 \pm 0.01$ & $0.0009 \pm 0.0006$ & 0.005 & 0.01 & 0.9 \\
CD14 (RU) & $0.16 \pm 0.08$ & $0.06 \pm 0.02$ & $<0.0001$ & 0.11 & 0.6 \\
HMOX1 (RU) & $0.024 \pm 0.01$ & $0.010 \pm 0.004$ & $<0.0001$ & - & - \\
\hline
\end{tabular}

The data are expressed as mean $\pm \mathrm{SD}$ or median (interquartile range)

${ }^{\text {a }}$ Bivariate correlation between the change of HMOX1 gene expression and the change of clinical variables and expression of adipose tissue- related genes

RU, relative units of gene expression relative to PPIA as endogenous control
mRNA levels, whereas iron chelation using DFO (20 $\mu \mathrm{mol} / \mathrm{l})$ exerted opposite effects. As expected, the major inductor of HMOX1 mRNA levels was hemin $(60 \mu \mathrm{mol} / 1)$, both in fully differentiated adipocytes (Fig. 4g) and during adipocyte differentiation (Fig. 5a). A significant reduction in intracellular lipid accumulation (Fig. 5b) and reduced adipogenic (ADIPOQ, FABP4, SLC2A4 and PLIN1) gene expression (Fig. $5 \mathrm{c}-\mathrm{f}$ ) was observed after hemin administration. Increased inflammatory (IL8,TNF) mRNAs (Fig. 5g-h), increased markers of intracellular iron accumulation (FTL, CYBA and SLC40A1) and reduced TFRC1 mRNA levels were also observed (Fig. 5i-1). Functionally, hemin led to a significant decrease in glucose uptake (Fig. $5 \mathrm{~m}$ ), basal respiration (Fig. 5n) and spare respiratory capacity (Fig. 5o).

\section{Discussion}

In contrast to haem oxygenase 2 (HMOX2), which is constitutively expressed in many tissues, HMOX1 is a facultative gene and is expressed at a relatively low level in most tissues. HMOX1 expression is regulated at transcriptional level being mainly induced by its substrate (haem), iron, oxidative stress and inflammation [26]. Facultative genes need precise regulation and their mRNA levels generally correlated with protein levels. In fact, a large number of studies have demonstrated that HMOX1 activity is proportional to $H M O X 1 \mathrm{mRNA}$ and protein levels $[27,28]$. Thus, we investigated $H M O X 1 \mathrm{mRNA}$ levels as the main outcome in the current study; the association between $H M O X 1 \mathrm{mRNA}$ and HMOX1 protein levels was also demonstrated in a subgroup of participants.

To the best of our knowledge this is the first study examining the possible role of HMOX1 in iron accumulation, mitochondrial respiratory function and adipogenesis in human adipocytes and adipose tissue in obese and non-obese participants.

HMOX1 and markers of iron accumulation in adipose tissue Iron accumulation in adipose tissue in obesity is detrimental for adipogenesis [7, 9, 10, 13-15]. In the current study, hemin-induced HMOX1 activity resulted in raised intracellular iron accumulation-related (FTL, SLC4OA1 and CYBA) markers and concordantly decreased TFRC mRNA levels. In agreement with these data, the association between tissue iron and HMOX1 gene expression and activity has been demonstrated in brain [29, 30], aorta [31] and liver [32]. Furthermore, a positive association between total body iron and HMOX1 activity has been reported [33]. In addition, intracellular free-iron-produced reactive oxygen species (ROS) are important inductors of HMOX1 activity [27, 28]. For this reason, a bidirectional regulation between HMOX1 activity and intracellular iron levels should be considered. In fact, in this study (Fig. 4d-f) iron administration in preadipocytes and adipocytes and during adipocyte differentiation resulted in a significant upregulation of HMOX1 gene expression, which was attenuated by DFO (an iron chelator) administration. $H M O X 1$ gene expression was positively correlated with gene expression markers of adipose tissue iron accumulation 
a

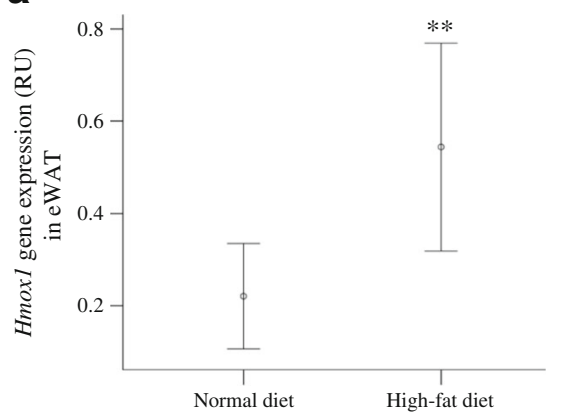

d
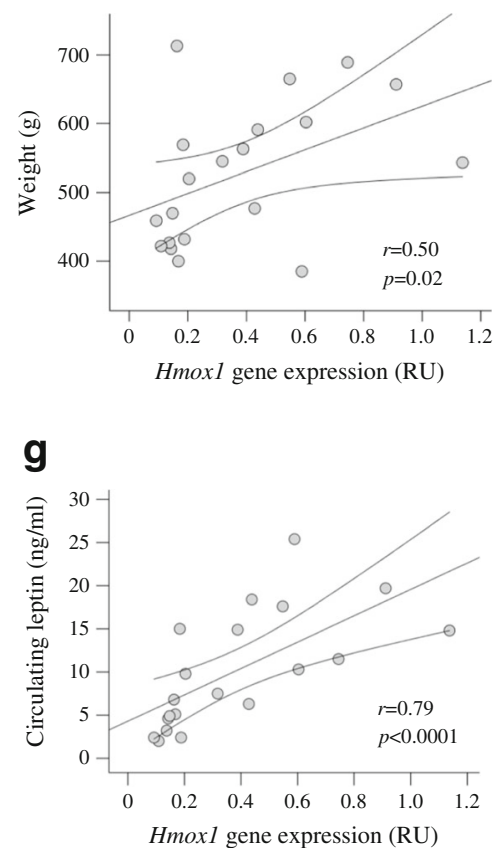

b

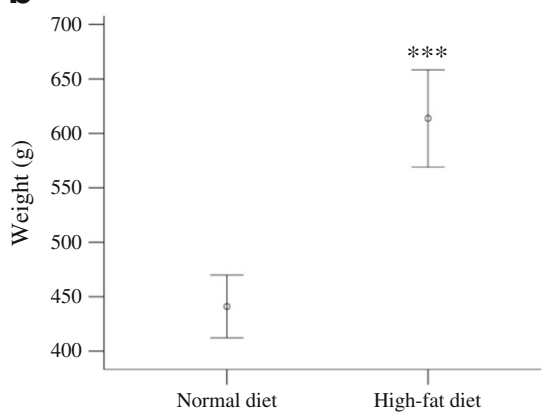

e

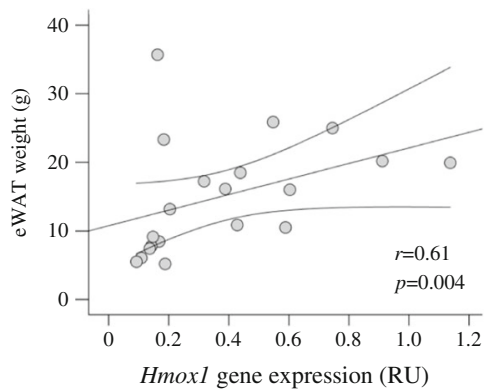

h

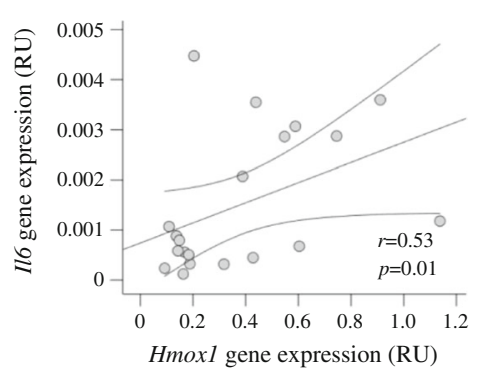

C

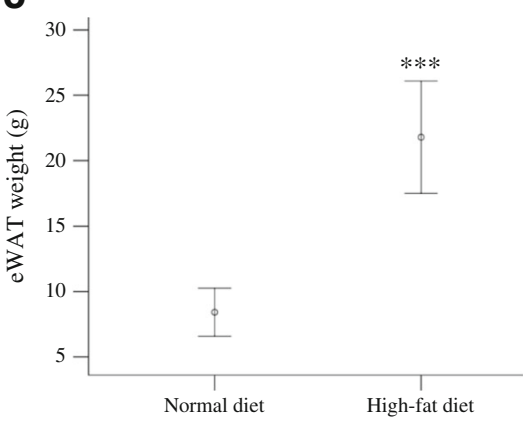

f

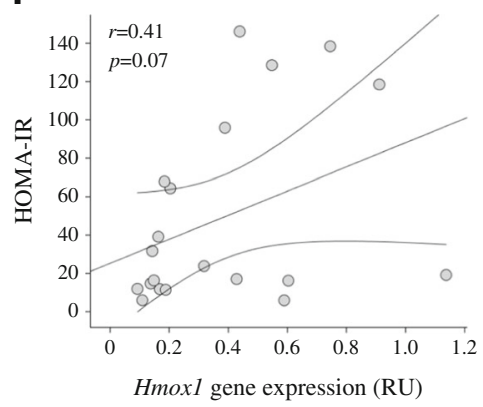

i

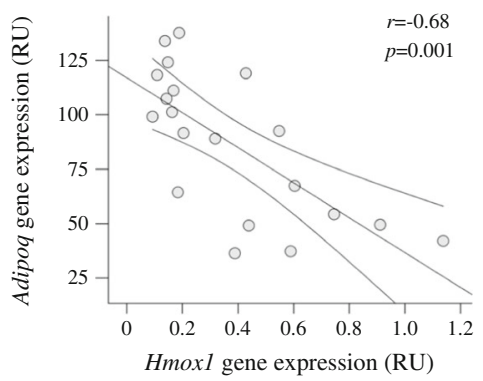

Fig. 3 (a-c) Effects of HFD in Hmoxl mRNA (a), weight (b) and eWAT weight $(\mathbf{c})$ in rats. $* * p<0.01, * * * p<0.001$ compared with normal diet. Error bars show $95 \%$ CI. (d-i) Bivariate correlation between eWAT
Hmox1 mRNA and weight (d), eWAT weight (e), HOMA-IR (f), circulating leptin (g), and eWAT Il6 (h) and Adipoq (i) mRNA

resulted in a significant alteration in mitochondrial respiratory function, decreasing basal respiration and spare respiratory capacity, two functional measures of mitochondrial function [21, 34]. Supporting these data, in this study HMOX1 gene expression was negatively correlated with gene expression markers of mitochondrial biogenesis (PPARGC1A, TFAM) even after controlling for age and BMI. Previous studies demonstrated the negative effects of HMOX1 on mitochondrial function in macrophages [21] and hepatocytes [35]. Since iron overload impairs mitochondrial function [36-38], it seems plausible that HMOX1 activity-associated adipocyte iron accumulation might contribute to attenuated mitochondrial respiratory function. The importance of mitochondrial function in adipocyte differentiation [39-41], adipocyte physiology [34], and the possible role of iron homeostasis in mitochondrial function and adipogenesis [10, 15] is well known. 
Fig. $4 H M O X 1$ gene expression in time course of adipocyte differentiation (a) and in adipose tissue subfractions (b). $* p<0.05$ compared with adipocytes;

$* * p<0.01$ compared with adipocytes or day 0 . Effects of $\mathrm{MCM}(2.5 \%)(\mathbf{c}), \mathrm{FeSO}_{4}(\mathrm{Fe}, 3$ and $30 \mu \mathrm{g} / \mathrm{ml})$ and DFO (20 $\mu \mathrm{mol} / \mathrm{l})(\mathbf{d})$ on HMOX1 gene expression during adipocyte differentiation at day 14 . $* p<0.05$, ** $p<0.01$ compared with differentiated adipocytes. Effects of $\mathrm{FeSO}_{4}(\mathrm{Fe}, 3$ and $30 \mu \mathrm{g} / \mathrm{ml})$ and DFO $(20 \mu \mathrm{mol} / \mathrm{l})$ on $H M O X 1$ gene expression in pre-adipocytes (e) and in adipocytes (f) after $72 \mathrm{~h}$. Effects of hemin $(60 \mu \mathrm{mol} / \mathrm{l})$ on HMOXI gene expression in adipocytes after $48 \mathrm{~h}$ (g). $* p<0.05$, $* * p<0.01$ compared with vehicle. Diff, differentiated; nondiff, non-differentiated b

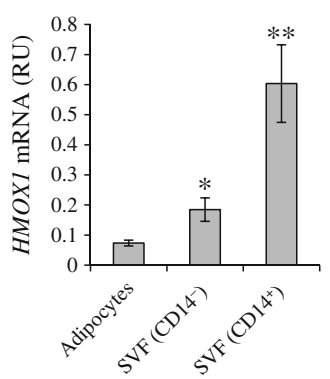

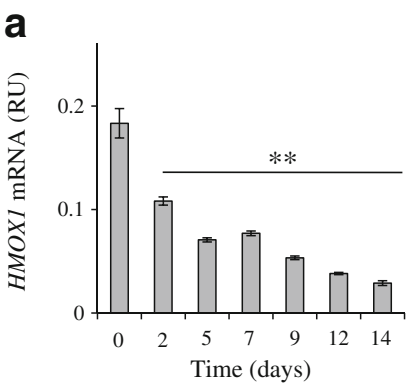

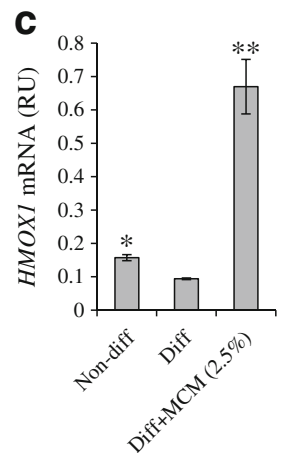

d

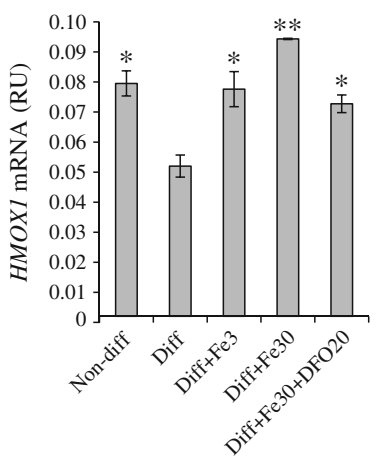

e

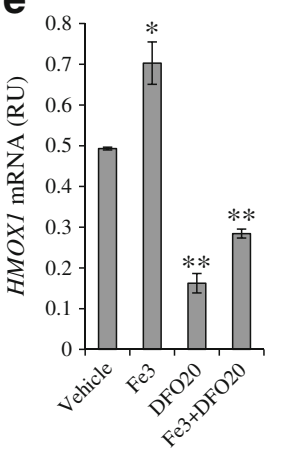

f

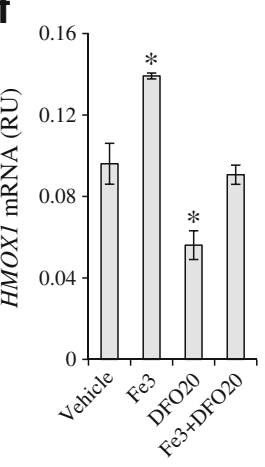

g

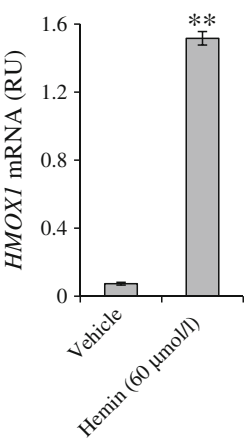

HMOX1 and human adipogenesis Hemin-induced HMOX1 expression resulted in decreased lipid droplet development in parallel with a significant reduction in adipogenic gene expression. A recent study also found anti-adipogenic effects of HMOX1 in pigs [42]. Specifically, this study demonstrated that overexpression of human HMOX1 in pigs resulted in decreased subcutaneous fat tissue development and attenuated capacity of isolated adipose-derived stem cells to differentiate to adipocytes [42].

Interestingly, HMOX1 induction led to a significant reduction of basal and insulin-induced glucose uptake in concordance with the decrease in SLC2A4 (GLUT4) mRNA levels. Since glucose uptake is required for the generation of new adipocytes and adipogenesis [43-45], the negative effects of hemin administration on glucose uptake might explain in part these anti-adipogenic effects. In agreement with these experiments, HMOX1 gene expression decreased significantly during human adipocyte differentiation and was negatively correlated with gene expression markers of adipogenesis (PPARG, FASN, ACACA) and adipocyte insulin action $(S L C 2 A 4, I R S 1)$ in both VAT and SAT. Furthermore, in contrast with the expression of adipogenic genes, increased $H M O X 1$ mRNA levels were found in parallel with hyperglycaemia and HOMA-IR in obese participants. Weight gain led to increased Hmoxl in mice [21] and rats (current results). Consistently, bariatric surgery-induced weight loss resulted in decreased adipose tissue HMOXI mRNA. The change in $H M O X 1$ mRNA levels correlated with

changes in BMI, fat mass and adipose tissue markers of adipogenesis. However, no correlations were found between adipose tissue $H M O X 1$ gene expression and systemic insulin sensitivity. As mentioned above, the association between HMOX1 expression and insulin resistance is not clear [21-23]. Biliverdin and carbon monoxide are two additional products derived from HMOX1 activity that have been associated with improved glucose tolerance and insulin sensitivity [46, 47]. Possibly, these putative positive effects of biliverdin and carbon monoxide might partly counteract the negative effects of HMOX1-associated adipose tissue dysfunction on systemic insulin sensitivity. The systemic upregulation of the haem oxygenase system by hemin or by cobalt protoporphyrin improves some metabolic features in Zucker diabetic fatty rats [48] and in obese Wistar rats [49]. Specifically, in Zucker diabetic fatty rats, hemin induction of the haem oxygenase system normalised glucose levels and reduced perirenal adiposity and inflammation [48]. However, these positive effects were attenuated in Zucker lean controls [48]. In obese Wistar rats, cobalt protoporphyrin-induced HMOX1 exerted positive effects on kidneys improving endothelial dysfunction in association with increased circulating adiponectin levels [49]. These studies investigated the systemic effects of HMOX1 upregulation in rats, whereas the current study focused specifically in adipose tissue $H M O X 1$ expression in response to HFD-induced weight gain (in Wistar rats) or bariatric surgery-induced weight loss (in humans). For instance, current results demonstrated increased eWAT Hmoxl in 

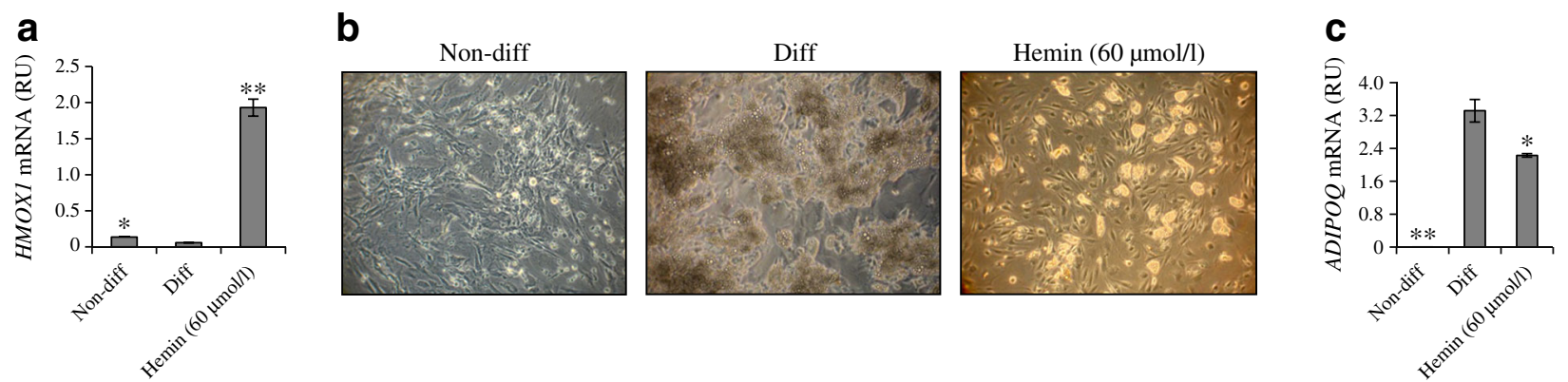
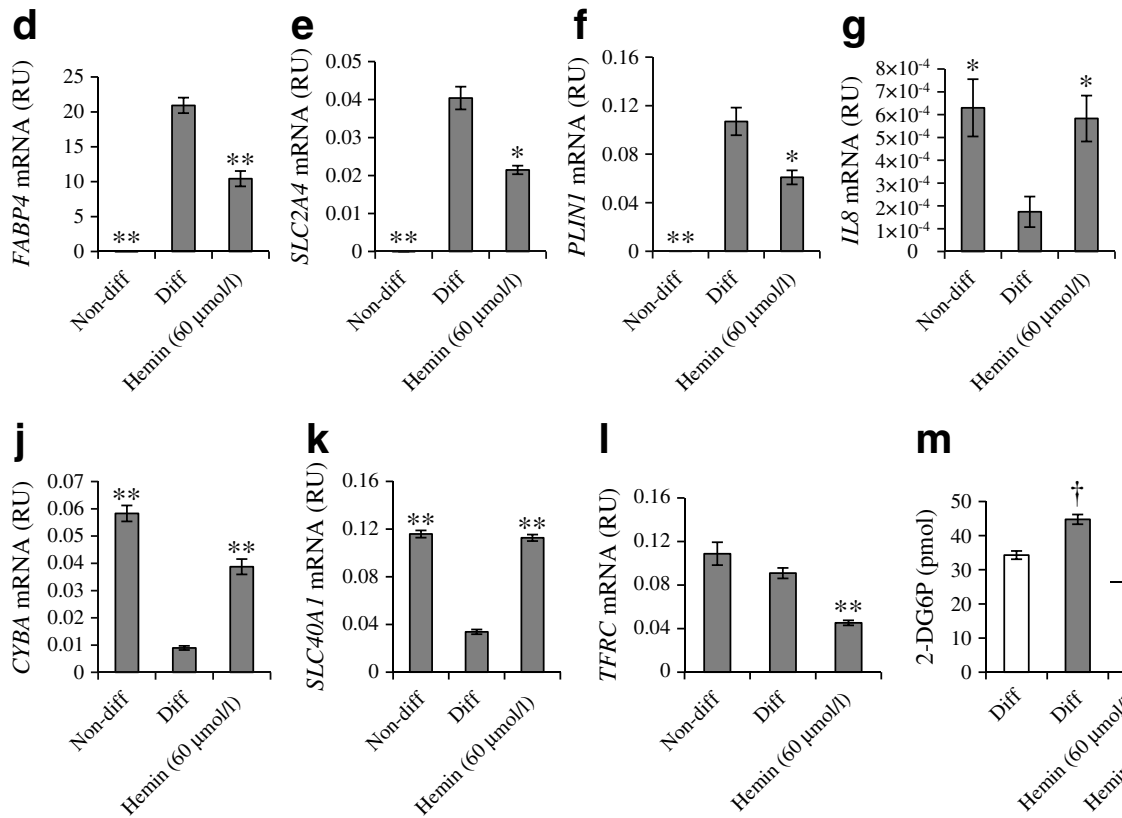

I

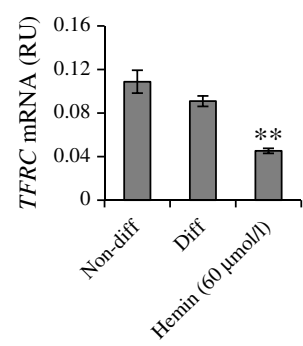

Fig. 5 Effects of hemin $(60 \mu \mathrm{mol} / 1)$ administration during adipocyte differentiation on $H M O X 1$ gene expression (a), intracellular lipid accumulation ( $\times 10$ magnification) (b), adipogenic-related $(A D I P O Q, F A B P 4$, $S L C 2 A 4, P L I N 1)(\mathbf{c}-\mathbf{f})$, inflammatory-related $(I L 8, T N F)(\mathbf{g}-\mathbf{h})$, iron accumulation-related (FTL, CYBA, SLC4OA1, TFRC) (i-l) gene expression markers, intracellular 2-DG6P in basal (white bars) and insulin stimulated

association with total weight, circulating leptin and decreased Adipoq gene expression in rats. For this reason, our current findings were not comparable with those obtained in the earlier studies. Nevertheless, a possible protective role of adipose tissue HMOX1 in humans cannot be excluded. Further studies are required to investigate specifically the effects of adipose tissue HMOX1 induction on obesity-associated metabolic disturbances and insulin resistance.

HMOX1 and adipose tissue inflammation As expected, we observed bidirectional influences between HMOX1 and inflammatory factors [21]. MCM (enriched with a mixture of inflammatory cytokines) induced adipocyte $H M O X 1$ mRNA levels, while hemin-induced HMOX1 activity increased adipocyte inflammatory cytokines (TNF, IL8). HMOXI mRNA levels were associated with gene expression of inflammatory cytokines in human adipose tissue and negatively correlated with $C D 206 / C D 68$ ratio (an M2 macrophage marker). In rats, HFD [50]. m

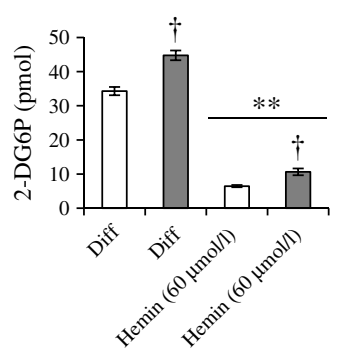

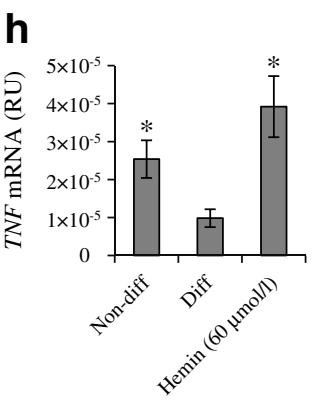

n

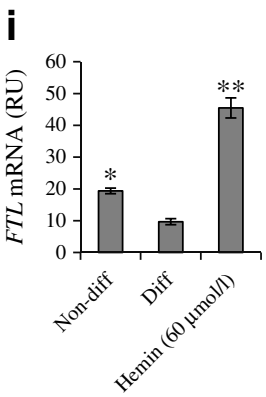

o
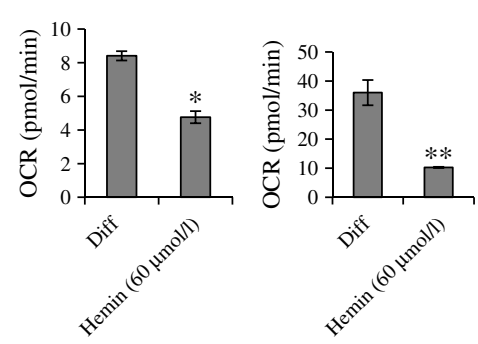

(grey bars) conditions (m) and on mitochondrial respiratory function (basal respiration [n] and spare respiratory capacity [o]) at day 14 . ${ }^{*} p<0.05, * * p<0.01$ compared with differentiated adipocytes. ${ }^{\dagger} p<0.05$ compared with basal. Diff, differentiated; non-diff, non-differentiated; OCR, oxygen consumption rate

HFD-induced weight gain resulted in increased Hmox 1 mRNA levels in association with $I l 6$ in eWAT. Some products derived from the HMOX1 catalytic activity also promoted adipose tissue macrophage infiltration and inflammation in mice fed an

Current findings regarding the importance of haem in adipogenesis [20], the precise regulation in intracellular haem levels through HMOX1 activity required to avoid ROSinduced cellular damage [26, 27], and the importance of iron and its fine-tuned regulation in adipogenesis $[7,10]$ envision a possible scenario, in which a progressive increase of fat accretion (parallel to obesity) leads to increased intracellular haem levels and, in consequence, to induced $H M O X 1$ gene expression and activity. Since HMOX1 is an inducible enzyme required for haem degradation, increased HMOX1 activity enhances the conversion of haem into ferrous iron [21], resulting in obesity-associated adipose tissue iron accumulation, which promotes adipose tissue dysfunction [7, 12]. 
In conclusion, $H M O X 1$ is proposed as an important marker of iron excess-induced adipose tissue dysfunction in human obesity.

Acknowledgements We acknowledge the technical assistance of E. Loshuertos and O. Rovira (both from Endocrinology, IdIBGi, Spain). We are indebted to the IDIBGI Biobank, integrated in the Spanish National Biobank Network, for the sample and data procurement.

Data availability statement Data sharing is not applicable to this article because of patient confidentiality; all relevant data has been included in the paper and ESM.

Funding This work was partially supported by research grants FIS PI12/02631 and PI15/01934 from the Instituto de Salud Carlos III from Spain and was also supported by Fondo Europeo de Desarrollo Regional (FEDER) funds. CIBEROBN Fisiopatología de la Obesidad y Nutrición is an initiative from the Instituto de Salud Carlos III from Spain.

Duality of interest The authors declare that there is no duality of interest associated with this manuscript.

Contribution statement JMM-N and JMF-R participated in study design and analysis of data. FO, AR, JL, SB and MS-M participated in acquisition of data. WR and GF participated in interpretation of data. JMM-N and JMF-R wrote and edited the manuscript. FO, AR, JL, SB, MS-M, WR and GF revised the manuscript critically for important intellectual content. All authors participated in final approval of the version to be published. JMM-N and JMF-R are the guarantors of this work.

\section{References}

1. Pellegrinelli V, Carobbio S, Vidal-Puig A (2016) Adipose tissue plasticity: how fat depots respond differently to pathophysiological cues. Diabetologia 59:1075-1088

2. Klöting N, Blüher M (2014) Adipocyte dysfunction, inflammation and metabolic syndrome. Rev Endocr Metab Disord 15:277-287

3. Landgraf K, Rockstroh D, Wagner IV et al (2015) Evidence of early alterations in adipose tissue biology and function and its association with obesity-related inflammation and insulin resistance in children. Diabetes 64:1249-1261

4. Rossmeislová L, Malisová L, Kracmerová J et al (2013) Weight loss improves the adipogenic capacity of human preadipocytes and modulates their secretory profile. Diabetes 62:1990-1995

5. Han MS, Jung DY, Morel C et al (2013) JNK expression by macrophages promotes obesity-induced insulin resistance and inflammation. Science 339:218-222

6. Gustafson B, Gogg S, Hedjazifar S, Jenndahl L, Hammarstedt A, Smith U (2009) Inflammation and impaired adipogenesis in hypertrophic obesity in man. Am J Physiol Endocrinol Metab 297:E999-E1003

7. Gabrielsen JS, Gao Y, Simcox JA et al (2012) Adipocyte iron regulates adiponectin and insulin sensitivity. J Clin Invest 122:35293540

8. Dongiovanni P, Ruscica M, Rametta R et al (2013) Dietary iron overload induces visceral adipose tissue insulin resistance. Am J Pathol 182:2254-2263

9. Moreno-Navarrete JM, Novelle MG, Catalán V et al (2014) Insulin resistance modulates iron-related proteins in adipose tissue. Diabetes Care 37:1092-1100
10. Moreno-Navarrete JM, Ortega F, Moreno M, Ricart W, FernándezReal JM (2014) Fine-tuned iron availability is essential to achieve optimal adipocyte differentiation and mitochondrial biogenesis. Diabetologia 57:1957-1967

11. Fernández-Real JM, Blasco G, Puig J et al (2016) Adipose tissue $\mathrm{R} 2 *$ signal is increased in subjects with obesity: a preliminary MRI study. Obesity (Silver Spring) 24:352-358

12. Orr JS, Kennedy A, Anderson-Baucum EK et al (2014) Obesity alters adipose tissue macrophage iron content and tissue iron distribution. Diabetes 63:421-432

13. Moreno M, Ortega F, Xifra G, Ricart W, Fernández-Real JM, Moreno-Navarrete JM (2015) Cytosolic aconitase activity sustains adipogenic capacity of adipose tissue connecting iron metabolism and adipogenesis. FASEB J 29:1529-1539

14. Moreno-Navarrete JM, Moreno M, Ortega F et al (2016) CISD1 in association with obesity-associated dysfunctional adipogenesis in human visceral adipose tissue. Obesity (Silver Spring) 24:139-147

15. Kusminski CM, Holland WL, Sun K et al (2012) MitoNEET-driven alterations in adipocyte mitochondrial activity reveal a crucial adaptive process that preserves insulin sensitivity in obesity. Nat Med 18:1539-1549

16. Bao W, Rong Y, Rong S, Liu L (2012) Dietary iron intake, body iron stores, and the risk of type 2 diabetes: a systematic review and meta-analysis. BMC Med 10:119

17. Fernández-Cao JC, Arija V, Aranda N et al (2013) Heme iron intake and risk of new-onset diabetes in a Mediterranean population at high risk of cardiovascular disease: an observational cohort analysis. BMC Public Health 13:1042

18. Pan A, Sun Q, Bernstein AM, Manson JE, Willett WC, Hu FB (2013) Changes in red meat consumption and subsequent risk of type 2 diabetes mellitus: three cohorts of US men and women. JAMA Intern Med 173:1328-1335

19. de Oliveira Otto MC, Alonso A, Lee DH et al (2012) Dietary intakes of zinc and heme iron from red meat, but not from other sources, are associated with greater risk of metabolic syndrome and cardiovascular disease. J Nutr 142:526-533

20. Kumar N, Solt LA, Wang Y et al (2010) Regulation of adipogenesis by natural and synthetic REV-ERB ligands. Endocrinology 151: 3015-3025

21. Jais A, Einwallner E, Sharif O et al (2014) Heme oxygenase-1 drives metaflammation and insulin resistance in mouse and man. Cell 158:25-40

22. Nicolai A, Li M, Kim DH et al (2009) Heme oxygenase-1 induction remodels adipose tissue and improves insulin sensitivity in obesityinduced diabetic rats. Hypertension 53:508-515

23. Li M, Kim DH, Tsenovoy PL et al (2008) Treatment of obese diabetic mice with a heme oxygenase inducer reduces visceral and subcutaneous adiposity, increases adiponectin levels, and improves insulin sensitivity and glucose tolerance. Diabetes 57:1526-1535

24. Shakeri-Manesch S, Zeyda M, Huber J, Ludvik B, Prager G, Stulnig TM (2009) Diminished upregulation of visceral adipose heme oxygenase-1 correlates with waist-to-hip ratio and insulin resistance. Int J Obes (Lond) 33:1257-1264

25. Mannerås-Holm L, Benrick A, Stener-Victorin E (2014) Gene expression in subcutaneous adipose tissue differs in women with polycystic ovary syndrome and controls matched pair-wise for age, body weight, and body mass index. Adipocyte 3:190-196

26. Chang M, Xue J, Sharma V, Habtezion A (2015) Protective role of hemeoxygenase-1 in gastrointestinal diseases. Cell Mol Life Sci 72: $1161-1173$

27. Siow RCM, Sato H, Mann GE (1999) Heme oxygenase-carbon monoxide signalling pathway in atherosclerosis: anti-atherogenic actions of bilirubin and carbon monoxide? Cardiovasc Res 41: 385-394

28. Lee TS, Chau LY (2002) Heme oxygenase-1 mediates the antiinflammatory effect of interleukin-10 in mice. Nat Med 8:240-246 
29. Wang LF, Yokoyama KK, Lin CL et al (2016) Knockout of ho-1 protects the striatum from ferrous iron-induced injury in a malespecific manner in mice. Sci Rep 6:26358

30. Lee JY, Keep RF, He Y, Sagher O, Hua Y, Xi G (2010) Hemoglobin and iron handling in brain after subarachnoid hemorrhage and the effect of deferoxamine on early brain injury. J Cereb Blood Flow Metab 30:1793-1803

31. Ishizaka N, Saito K, Mori I, Matsuzaki G, Ohno M, Nagai R (2005) Iron chelation suppresses ferritin upregulation and attenuates vascular dysfunction in the aorta of angiotensin II-infused rats. Arterioscler Thromb Vasc Biol 25:2282-2288

32. Brown KE, Dennery PA, Ridnour LA et al (2003) Effect of iron overload and dietary fat on indices of oxidative stress and hepatic fibrogenesis in rats. Liver Int 23:232-242

33. Arredondo M, Jorquera D, Carrasco E, Albala C, Hertrampf E (2007) Microsatellite polymorphism in the heme oxygenase-1 gene promoter is associated with iron status in persons with type 2 diabetes mellitus. Am J Clin Nutr 86:1347-1353

34. Yin X, Lanza IR, Swain JM, Sarr MG, Nair KS, Jensen MD (2014) Adipocyte mitochondrial function is reduced in human obesity independent of fat cell size. J Clin Endocrinol Metab 99:E209-E216

35. Cheng Z, Guo S, Copps K et al (2009) Foxol integrates insulin signaling with mitochondrial function in the liver. Nat Med 15: 1307-1311

36. Lee HJ, Choi JS, Lee HJ, Kim WH, Park SI, Song J (2015) Effect of excess iron on oxidative stress and gluconeogenesis through hepcidin during mitochondrial dysfunction. J Nutr Biochem 26: 1414-1423

37. Martelli A, Schmucker S, Reutenauer L et al (2015) Iron regulatory protein 1 sustains mitochondrial iron loading and function in frataxin deficiency. Cell Metab 21:311-322

38. Gao X, Qian M, Campian JL et al (2010) Mitochondrial dysfunction may explain the cardiomyopathy of chronic iron overload. Free Radic Biol Med 49:401-407

39. De Pauw A, Tejerina S, Raes M, Keijer J, Arnould T (2009) Mitochondrial (dys)function in adipocyte (de)differentiation and systemic metabolic alterations. Am J Pathol 175:927939
40. Lu RH, Ji H, Chang ZG, Su SS, Yang GS (2010) Mitochondrial development and the influence of its dysfunction during rat adipocyte differentiation. Mol Biol Rep 37:2173-2182

41. Zhang Y, Marsboom G, Toth PT, Rehman J (2013) Mitochondrial respiration regulates adipogenic differentiation of human mesenchymal stem cells. PLoS One 8, e77077

42. Park EJ, Koo OJ, Lee BC (2015) Overexpressed human heme oxygenase-1 decreases adipogenesis in pigs and porcine adiposederived stem cells. Biochem Biophys Res Commun 467:935-940

43. Liao W, Nguyen MT, Yoshizaki T et al (2007) Suppression of PPAR- $\gamma$ attenuates insulin-stimulated glucose uptake by affecting both GLUT1 and GLUT4 in 3T3-L1 adipocytes. Am J Physiol Endocrinol Metab 293:E219-E227

44. Shepherd PR, Gnudi L, Tozzo E et al (1993) Adipose cell hyperplasia and enhanced glucose disposal in transgenic mice overexpressing GLUT4 selectively in adipose tissue. J Biol Chem 268: 22243-22246

45. Hauner H, Röhrig K, Spelleken M, Liu LS, Eckel J (1998) Development of insulin-responsive glucose uptake and GLUT4 expression in differentiating human adipocyte precursor cells. Int J Obes Relat Metab Disord 22:448-453

46. Ikeda N, Inoguchi T, Sonoda N et al (2011) Biliverdin protects against the deterioration of glucose tolerance in $d b / d b$ mice. Diabetologia 54:2183-2191

47. Hosick PA, AlAmodi AA, Hankins MW, Stec DE (2015) Chronic treatment with a carbon monoxide releasing molecule reverses dietary induced obesity in mice. Adipocyte 5:1-10

48. Ndisang JF, Jadhav A, Mishra M (2014) The heme oxygenase system suppresses perirenal visceral adiposity, abates renal inflammation and ameliorates diabetic nephropathy in Zucker diabetic fatty rats. PLoS One 9, e87936

49. Liu X, Zang P, Han F, Hou N, Sun X (2015) Renal protective effects of induction of haem oxygenase- 1 combined with increased adiponectin on the glomerular vascular endothelial growth factornitric oxide axis in obese rats. Exp Physiol 100:865-876

50. Huang JY, Chiang MT, Yet SF, Chau LY (2012) Myeloid heme oxygenase-1 haploinsufficiency reduces high fat diet-induced insulin resistance by affecting adipose macrophage infiltration in mice. PLoS One 7, e38626 